\title{
CORPOS "[I]LEGITIMOS": A PASSABILIDADE COMO TRÂNSITO E RECONHECIMENTO
}

DUQUE, Tiago. Gêneros Incríveis: um estudo sócio antropológico sobre as experiências de (não) passar por homem e/ou mulher. Campo Grande: Editora UFMS, 2017. 238 páginas.

Vivemos em um contexto que para compreender os outros, em diversos momentos, fazemos interpretações sobre as suas vivências externas, subjetividades, que são particulares. Fazemos "leituras" e afirmamos lugares sem de antemão ouvir as/os próprias/os sujeitos das suas histórias. São tentativas, algumas do senso comum, outras não, que buscam aproximar uma visão dessas/es sujeitos para o mais próximo do inteligível, esquecendo-se que muitas das experiências delas/es "fogem" da nossa visão encaixotada do que é "ser homem" e "ser mulher", particular, único, dissidente, entre outras possíveis e múltiplas classificações, que não cabem nas categorias hegemônicas.

Desta forma, o autor deste livro, Tiago Duque, através de uma etnografia, traz com sensibilidade as experiências das/os sujeitos, contadas por suas/seus próprias/ os interlocutores/as. O autor, teve sua inserção no campo através do ativismo LGBT, na cidade de Campinas. O mesmo, escreveu o livro, Montagens e desmontagens: desejo, estigma e vergonha entre travestis adolescentes, publicado em 2011 pela editora Annablume, o qual serviu de contribuição para este atual. Ainda que o passar por não tivesse aparecido no campo de seu primeiro livro, a montagem estratégica ${ }^{2}$ (DUQUE, 2011), apresentada pelas travestis adolescentes, já apontava para um regime de visibilidade, semelhante ao passar por, mas neste caso demarcado por uma geração de novas travestis e mais focado no gênero e não no "sexo".

Ainda no prefácio, escrito por Karla Bessa3, é apresentado a delicadeza com que o autor escuta/olha/atenta-se e "lê" o "outro". O que fica evidente na escrita do livro são as questões, e problematizações que envolvem, principalmente, as experiências de pessoas trans, isto é, quanto a experiências de reconhecimento/abjeção, o que

1 Doutor em Ciências Sociais pela Universidade Estadual de Campinas. Docente do Programa de Pós-
Graduação em Educação do Campus do Pantanal (CPAN) e do Programa de Antropologia Social da
Faculdade de Ciências Humanas (FACH) da Universidade Federal de Mato Grosso do Sul (UFMS).
Coordenador do Impróprias - Grupo de Pesquisa em Gênero, Sexualidade e Diferenças.
2 A montagem estratégica permite uma maior fluidez entre o masculino e feminino, o uso de adereços
conhecidos socialmente como femininos, como exemplo, roupas, cabelos e trejeitos, permitem
um reconhecimento não definitivo, mas pontual sobre o "estar sendo" travesti. Essas montagens
momentâneas são agenciadas de acordo com seus desejos e algumas expectativas vindas das demandas
sociais da cultura em que estão inseridas (DUQUE, 2011). 3 Doutora em História pela Universidade Estadual de Campinas.

Carla Cristina de Souza

Universidade Federal de Mato Grosso do Sul (UFMS). E-mail: carlinhacdsouza@gmail.com 
está intimamente ligado aos atos/aparatos que são utilizados para compor um corpo "inteligível", entre diferentes códigos que atribuem a um sujeito uma legitimidade diante do olhar do "outro", essa/e deixa (ou não) de ser aceito socialmente.

Esse ser inteligível é o que o autor vai pensar com o uso do termo passar por, antes utilizado como ele mesmo explica, por sujeitos do próprio meio. Essas experiências de (não) passabilidade será apresentada durante o livro nas histórias de 8 interlocutoras/ es, que subvertem a ordem cristalizadora do gênero e sexualidade, apresentando a fluidez com que se pode (re)inventar, re/(des)construir a identidade, um processo sempre em andamento e com múltiplas possibilidades de expressões. Isso sem deixar, inclusive, de também reiterar normas e convenções normalmente esperadas.

$\mathrm{O}$ interessante, e aqui vale ressaltar, aspecto que o livro traz é que as experiências de passabilidade não estão restritas aos sujeitos tidos como dissidentes, tendo em vista que somos "educados" a performatizar os trajetos, percursos, do que é socialmente aceito como ser mulher ou homem (restrito e aceito comumente apenas em binarismos), e esse ponto também é presente diante daquelas/es que nasceram e se identificam/reconhecem com seu gênero desde o nascimento. Isto é, uma biomulher ${ }^{4}$ (PRECIADO, 2008) em algum contexto, poderá passar por uma experiência de ter que (re)performatizar aspectos do que "é ser mulher", para passar por mulher, ser reconhecida como tal segundo os códigos legitimados socialmente, pois atingir a passabilidade requer um reconhecimento do "outro".

Um dos potenciais do livro é apresentado a partir da análise das experiências das/os agentes trazidas pelo autor, que mostra quanto o passar por não está somente restrito as normas de gênero, mas engloba outros marcadores sociais da diferença que em intersecções favorecem uma passabilidade. Uma das histórias retratadas é de Morgana, segunda ela mesma, uma "mulher transexual lésbica”. A mesma conta que em determinado contexto a identificaram como uma mulher grávida, devido ao seu corpo gordo, neste sentido, o que lhe garantiu uma passabilidade, e feminilidade, não foram aparatos tidos como do "sexo feminino", como jóias, brincos entre outros, mas a gordura, que também lhe garante ter os seios maiores, mesmo sem silicone e com marcas na maior parte das vezes reconhecidas como masculinas, como a calvície e a barba.

No primeiro momento, o autor apresenta no que implica o passar por, compreendido como uma dinâmica mais fluída do trânsito visível/invisível, e explica porque não usa a categoria de "armário" (SEDGWICK, 1998) para compor suas análises, fazendo uma crítica ao binarismo que o termo em certa medida emprega quando usado sem criticidade. Isso pode ser percebido nas próprias experiências da passabilidade, pois estas envolvem um "jogo" de possibilidades que não se restringe estar em um lugar ou outro, mas envolve um contínuo fluxo de ir evir. O autor, inspirado em Sedgwick (1998), explica que não há como localizar-se binariamente, dentro ou fora do "armário", até porque estes lugares não existem de fato enquanto possíveis realidades. Afinal, mesmo para as/os mais “assumidas/os”, poderá haver um contexto

4 O uso de bio-mulher não pretende apontar uma diferença entre o que é "real"/biológico ou "irreal", pois ambos corpos são produzidos, sendo o uso do bio apenas um indicativo político, em certa medida, "irônico" do que seria um "dado natural". 
em que seja estratégico/necessário assumir uma performance que a/o "levará para dentro" do "armário", e essas experiências são legítimas, tendo em vista que estamos permeadas/os por regimes de visibilidade/conhecimento. Segundo a minha leitura, a passabilidade, assim como o "armário", mesmo sendo categorias diferentes, possuem certa relação, vemos que não dependem somente das/os sujeitos passar por ou estar no "armário", mesmo para as/os mais assumidas/os e/ou visíveis.

Já no segundo capítulo, é nos apresentado as/os interlocutoras/es que contribuíram para o processo da pesquisa e como foram selecionadas/os. A princípio, a escolha foi a partir das experiências identificadas durante o trabalho de campo. Posteriormente, a partir das indicações das/os entrevistadas/os, sendo essas/es as/os mais variadas/os sujeitos em termos de raça/cor, classe, idade, gênero e sexualidade. Algumas das aproximações, quanto às indicações, se deram, logo, a partir do olhar do "outro". Também é destacado neste momento que não é intuito analisar as experiências somente a partir de quem atinge o sucesso na passabilidade, isso aparece quando são apresentadas as experiências das/os interlocutoras/es que foram identificadas/os pelos pares como não passáveis.

Ainda que haja um esforço dessa/e sujeito, com o uso de alguns atos/aparatos, como dito antes, conhecidos socialmente como pertencentes a determinados gêneros, eles não necessariamente são os destaques ou funcionam de forma positiva no sentido dealcançara passabilidade que se espera. Os limites dousodesses artefatos, por exemplo as roupas, que socialmente fariam essas/es sujeitos serem passáveis, variam de acordo também com o contexto em que estão performatizando. Isso aparece no livro quando, por meio das narrativas das/dos interlocutores/as, a busca ou não da passabilidade surge a partir de diferentes marcadores sociais (classe, raça/cor, gênero, sexualidade, idade, etc.) e dos corpos como um todo em diferentes espaços de interação, mostrando que o reconhecimento possui sentidos e possibilidades variavelmente distintas.

Adiante, no terceiro capítulo, são analisados os corpos, as imagens e os reconhecimentos de acordo com cada contexto dessas/es sujeitos, mostrando como somos regulados por regimes normatizadores, o que a noção foucaultiana chama de biopoder, sendo esta uma perspectiva muito útil para compreender as experiências das/ os interlocutoras/es desta pesquisa. Para apresentar um exemplo do que o autor quer nos dizer com as disciplinas dos corpos, (FOUCAULT, 2007), presente em um regime de biopoder, nos é contado a experiência vivida por Rafael. Segundo ele mesmo, "um homem transexual hétero, em transformação ainda”. Ele foi "orientado" a não fazer nenhum tipo de intervenção em seu órgão reprodutor que foi diagnosticado como saudável logo, não apresentado nenhum problema no que se referia a saúde, o que pressupõe um resultado não favorável para cirurgias. Sendo assim, orientado por seu médico, começou um "tratamento" que resultaria na "atrofiação" de suas trompas, a menstruação seria cessada, o que aumentaria as chances de uma intervenção cirúrgica para a extirpação total de seu útero. Isso, de fato, ocorreu. Assim, o reconhecimento que "legitimou" Rafael, aproximando-o do "homem ideal", se levarmos em consideração uma matriz heteronormativa (BUTLER, 2003), foi esse processo cirúrgico, um trânsito que alguns reconhecem como sendo necessário para trazer uma "coerência", 
inteligibilidade, normalidade do ser. Mesmo o órgão sexual-reprodutivo não sendo algo visualmente acessível nas relações cotidianas entre ele e as outras pessoas, o corpo tornou-se legitimado, pois o que importa, por exemplo, para uma/um juiza/ juiz no momento de aprovar a mudança do nome e do sexo, não é tanto se a pessoa é passável ou não, mas se fez a cirurgia.

Nesse quarto momento do livro, as vestimentas são o foco de análise. Algumas roupas nesta pesquisa foram apresentadas por interlocutoras/es com um forte peso no sentido de trazer visibilidade, mais do que o corpo em si. Isso porque, elas só têm significados que chegam a uma passabilidade dentro de determinados contextos e dependendo de quem usa determinada "moldura", segundo os termos do próprio autor. Algo interessante a se chamar atenção é que as roupas revelam uma das presentes características de nossa sociedade em relação ao que "podemos" identificar como "ser homem" e "ser mulher", e, dentro desse contexto, existem as roupagens "corretas" que fazem com que nos aproximamos de uma feminilidade ou masculinidade hegemônica, aquela que "devemos" seguir. Tendo em vista que, comumente, as/os interlocutoras/ es desta pesquisa estão expostas/os à violência, quando não atingem as expectativas de identificação de "ser homem ou mulher", as "molduras", e todo o aparato que "legitimaria" a passabilidade, se tornam importantes para as experiências dessas/es sujeitos.

Por fim, no quinto e último capítulo, há uma discussão sobre como são estratégicos os manuseios para ser reconhecida/o, tendo em vista que uma passabilidade pode tirar da marginalidade algumas/alguns sujeitos, livrando-as/os de serem rechaçadas/os e sofrerem violências diversas. $\mathrm{O}$ autor aponta que, mesmo quando sua/seu interlocutora/interlocutor não buscam ser reconhecidas/os por meio de uma visibilidade nos termos já existentes, e algumas vezes hegemônica, esse reconhecimento via o olhar do "outro", ainda constitui-se em termos normativos. Ainda que a abjeção não fosse foco deste estudo, algumas experiências intercruzam essa via do "não humano", dificultando o desejado reconhecimento. De toda forma, o que esses sujeitos buscam, em contextos de violência, é visibilizar o discurso do "direito/ respeito às diferenças”. Em locais que as relações, interações, como a rua, possam ser violentas, é interessante que essas/es sujeitos passem por, para não sofrerem algum tipo de rechaço, ao contrário, quando o local é "mais seguro", é interessante anunciar o "sexo" de origem, tendo em vista que essa visibilidade do que a pessoa foi e agora está sendo, se tornaria surpreendente para as pessoas que estão valorizando as/os mais diferentes. Por isso, o passar por deve ser visto enquanto um regime estratégico de visibilidade, reconhecimento e trânsitos.

\section{Referências bibliográficas}

BUTLER, Judith. Problemas de Gênero: feminismo e subversão da realidade. Rio de Janeiro: Civilização Brasileira, 2003. 
DUQUE, Tiago. Montagens e desmontagens: desejo, estigma e vergonha entre travestis adolescentes. São Paulo: Annablume, 2011.

FOUCAULT, Michel. História da sexualidade I: a vontade de saber. Rio de Janeiro: Edições Graal, 2007.

PRECIADO, Beatriz. Testo Yonqui. Madrid: Espasa Calpe, 2008.

SEDGWICK, Eve Kosofsky. Epistemologia del armario. Barcelona: Ediciones de La tempestad, 1998.

Recebido: 26/10/2018

Aceito: 9/7/2018 